\title{
Correction: Imatinib mesylate inhibits STAT5 phosphorylation in response to IL-7 and promotes T cell lymphopenia in chronic myelogenous leukemia patients
}

S. Thiant, M. M. Moutuou, P. Laflamme, R. Sidi Boumedine, D. M. Leboeuf, L. Busque, J. Roy and M. Guimond

Correction to: Blood Cancer Journal

https://doi.org/10.1038/bcj.2017.29

published online 7 April 2017

Following the publication of this article the authors noted that Grant numbers were omitted in the Acknowledgements section. This work was supported by grants from the Cancer Research Society of Canada (grants no. 16255 to M.G.) and from the Fond de Recherche Santé
Québec (grant no 20219 to J.R.) and in part by the Foundation de l'Hôpital Maisonneuve-Rosemont, Montreal, QC, CAN. The authors wish to apologize for any inconvenience caused.

Published online: 04 November 2020 